\title{
EUS-guided methylene blue injection into the pancreatic duct as a guide for pancreatic stenting after ampullectomy
}

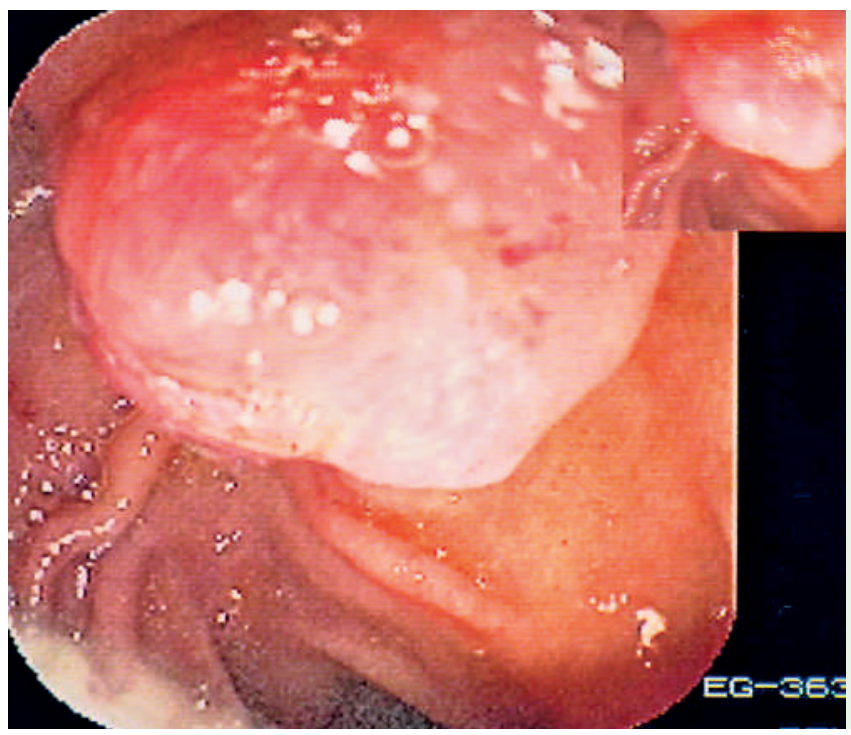

Figure 1 Prominent papilla of Vater with adenomatous aspect.

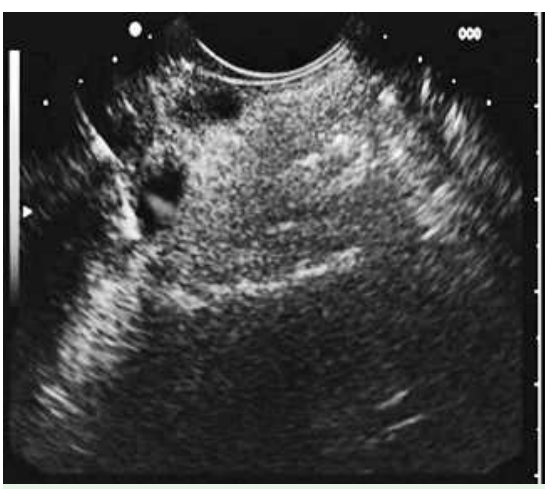

Figure 2 Endoscopic ultrasound view of the pancreatic head from the descending duodenum. A 25 -gauge needle $(N)$ is puncturing the pancreatic duct $(\mathrm{W})$ that presents a mild retropapillary dilation.

Methylene blue (MB) is an intravital stain, mostly used to demonstrate specialized epithelium in Barrett's esophagus [1], for locating the minor papilla during endoscopic retrograde cholangiopancreatography (ERCP) [2], or injected into the submucosa before endoscopic mucosal resection and polypectomy [3]. Endosonography (EUS)-guided injection of $\mathrm{MB}$ into the pancreatic duct (PD) has been described to identify the minor papilla after unsuccessful ERCP [4].

Endoscopic ampullectomy is a therapeutic approach for resecting the ampullary

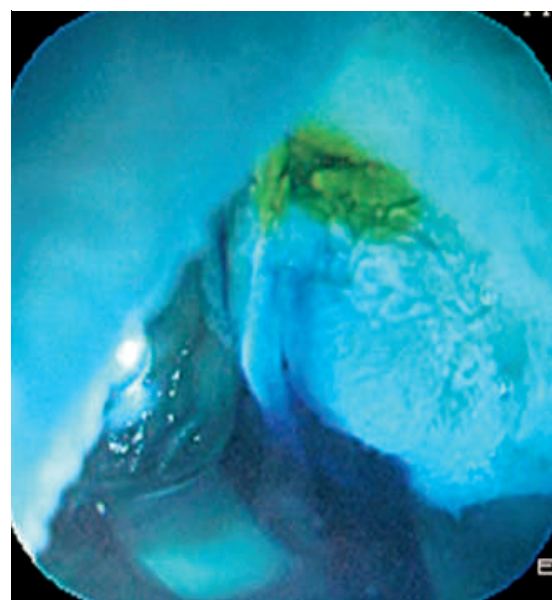

Figure 3 Endoscopic view of the biliary orifice with bile flow, and pancreatic orifice with methylene blue flow.

area in case of superficial tumors. This is a challenging procedure because of technical difficulties and the risk of postprocedural complications. A randomized controlled trial found that PD stenting after endoscopic snare excision of the ampulla in patients with papillary tumors [5] was more effective than not stenting in preventing postprocedure pancreatitis. Nevertheless PD cannulation during endoscopic retrograde pancreatography can be challenging; moreover, edema and artifacts due to electrocautery during ampullectomy can make it even harder to

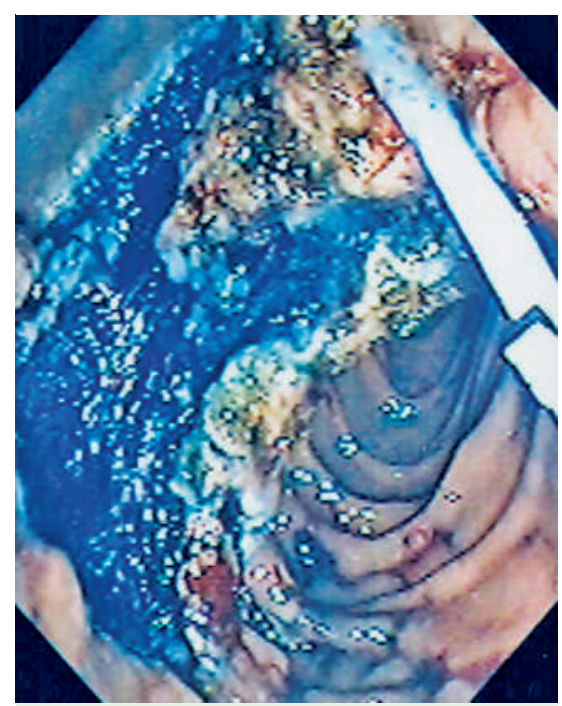

Figure 4 View after the ampullectomy, with a plastic stent in the pancreatic duct.

identify the pancreatic orifice. EUS is considered the best method for staging ampullary lesions and selecting those suitable for endoscopic resection.

We injected MB intraductally under EUS guidance in three patients with adenoma of the ampulla ( $\odot$ Figure 1 ) to help in detecting the pancreatic orifice and in placing a stent after ampullectomy. Two patients had PD dilation. A 25-gauge needle, primed with $\mathrm{MB}$ (methylthionine $100 \mathrm{mg} / 10 \mathrm{~mL}$, dilution $1: 20000$ ), was used to puncture the PD under EUS guidance ( $\bullet$ Figure 2 ). Then MB was slowly injected into the duct, and its flow was visible from the papillary orifice after a few seconds ( $\square$ Figure 3; video). After ampullectomy, performed during the same session, the MB flow was evident from the pancreatic orifice and was a guide for placing a stent in the PD ( $\bullet$ Figure 4). No complications were observed. All pancreatic stents were successful

\section{Video}

An 84-year-old woman with neurofibromatosis presented with abdominal pain, jaundice and fever. An oesophagogastroduodenoscopy with forceps biopsy showed an adenoma of the papilla.

Endoscopic ultrasound (EUS) was performed to stage the lesion: bile duct and pancreatic duct were dilated, without vegetations inside.

A 25-gauge needle, primed with methylene blue (dilution 1:20000, $3 \mathrm{~mL}$ ), was used to puncture the Wirsung under EUS guidance. Then, under EUS control, methylene blue was slowly injected into the duct and its flow observed from the papillary orifice after few seconds. 
thanks to the blue stain oozing from the pancreatic orifice, even in cases with edema due to electrosurgical current.

Endoscopy_UCTN_Code_TTT_1AS_2AD

Endoscopy_UCTN_Code_TTT_1AS_2AF

\section{S. Carrara ${ }^{1}$, P. G. Arcidiacono ${ }^{1}$,}

A. M. Diellou ${ }^{2}$, G. Mezzi ${ }^{1}$, M. Rossi ${ }^{1}$,

C. Boemo ${ }^{1}$, E. Masci ${ }^{1}$, P. A. Testoni ${ }^{1}$

${ }^{1}$ Division of Gastroenterology \& Gastrointestinal Endoscopy, University Vita-

Salute San Raffaele, Scientific Institute San Raffaele, Milan, Italy
2 Department of Gastroenterology, General Hospital of Athens G. Genimatas, Athens, Greece

\section{References}

1 Canto MI, Setrakian S, Petras RE et al. Methylene blue selectively stains intestinal metaplasia in Barrett's esophagus. Gastrointest Endosc 1996; 44: 1-7

2 Park SH, de Bellis M, McHenry L et al. Use of methylene blue to identify the minor papilla or its orifice in patients with pancreas divisum. Gastrointest Endosc 2003; 57: 358 363

3 Munakata A, Uno Y. Colonoscopic polypectomy with local injection of methylene blue. Tohoku J Exp Med 1994; 173: $377-$ 382

4 DeWitt J, McHenry L, Fogel E et al. EUS-guided methylene blue pancreatography for minor papilla localization after unsuccessful ERCP. Gastrointest Endosc 2004; 59: $133-136$

5 Harewood GC, Pochron NL, Gostout CJ. Prospective, randomized, controlled trial of prophylactic pancreatic stent placement for endoscopic snare excision of the duodenal ampulla. Gastrointest Endosc 2005; 62: 367-373
Bibliography

DOI 10.1055/s-2007-966242

Endoscopy 2007; 39: E151 - E152

(c) Georg Thieme Verlag KG Stuttgart · New York . ISSN 0013-726X

\section{Corresponding author}

\section{S. Carrara, MD}

Division of Gastroenterology \& Gastrointestinal Endoscopy

University Vita-Salute San Raffaele

Scientific Institute San Raffaele

Via Olgettina 60

20132 Milan

Italy

Fax: +39-02-26432504

carrara.silvia@hsr.it 